\title{
The Edinger-Westphal-Lateral Septum Urocortin Pathway and Its Relationship to Alcohol Consumption
}

\author{
Ryan K. Bachtell, ${ }^{1}$ Adam Z. Weitemier, ${ }^{1}$ Agustin Galvan-Rosas, ${ }^{1}$ Natalia 0. Tsivkovskaia, ${ }^{1}$ Fred 0. Risinger, ${ }^{1}$ \\ Tamara J. Phillips, ${ }^{1,2}$ Nicholas J. Grahame, ${ }^{3}$ and Andrey E. Ryabinin ${ }^{1}$ \\ ${ }^{1}$ Department of Behavioral Neuroscience, Oregon Health and Science University and Portland Alcohol Research Center, Portland, Oregon 97239, \\ ${ }^{2}$ Department of Veterans Affairs Medical Center, Portland, Oregon 97239, and ${ }^{3}$ Department of Psychiatry, Indiana University School of Medicine, \\ Indianapolis, Indiana 46202
}

Identifying and characterizing brain regions regulating alcohol consumption is beneficial for understanding the mechanisms of alcoholism. To this aim, we first identified brain regions changing in expression of the inducible transcription factor c-Fos in the alcoholpreferring C57BL/6J (B6) and alcohol-avoiding DBA/2J (D2) mice after ethanol consumption. Drinking a 5\% ethanol/10\% sucrose solution in a $30 \mathrm{~min}$ limited access procedure led to induction of c-Fos immunoreactivity in urocortin (Ucn)-positive cells of the EdingerWestphal nucleus (EW), suppression of c-Fos immunoreactivity in the dorsal portion of the lateral septum (LS) of both strains of mice, and strain-specific suppression in the intermediate portion of the LS and the CA3 hippocampal region. Because the EW sends Ucn projections to the LS, and B6 and D2 mice differ dramatically in EW Ucn expression, we further analyzed the Ucn EW-LS pathway using several genetic approaches. We find that D2 mice have higher numbers of Ucn-immunoreactive processes than B6 mice in the LS and that consumption of ethanol/sucrose in the F2 offspring of a B6D2 intercross positively correlates with Ucn immunoreactivity in the EW and negatively correlates with Ucn immunoreactivity in the LS. In agreement with these findings, we find that alcohol-avoiding male B6.D2 Alcp1 line 2.2 congenic mice have lower Ucn immunoreactivity in the EW than male B6.B6 mice. Finally, we also find that HAP mice, selectively bred for high alcohol preference, have higher Ucn immunoreactivity in EW, than LAP mice, selectively bred for low alcohol preference. Taken together, these studies provide substantial evidence for involvement of the EW-LS Ucn pathway in alcohol consumption.

Key words: urocortin; ethanol; Edinger-Westphal; septum; inducible transcription factor; self-administration

To develop effective treatments of alcoholism, it is important to identify and characterize the neural systems underlying pathological patterns of alcohol use. Identification of brain regions in which neural activity is changed after drinking alcoholcontaining solutions has been partially accomplished by analyzing inducible transcription factor (ITF) expression (Topple et al., 1998; Bachtell et al., 1999; Ryabinin et al., 2001; Weitemier et al., 2001). This approach is based on the notion that basal expression of ITFs (c-Fos, c-Jun, and Zif268) in neurons is very low. After neuronal stimulation, a rapid, transient induction of these proteins occurs (Morgan et al., 1987; Sagar et al., 1988). With the use of ITF expression mapping and 2-deoxyglucose mapping, it has been observed that self-administration of alcohol-containing solutions produces patterns of neural activity distinct from those observed after involuntary alcohol administration (WilliamsHemby and Porrino, 1994; Porrino et al., 1998).

These studies are limited, however, in that neural changes were studied after alcohol consumption in rodents predisposed to consuming large amounts of alcohol. Because the neural systems in such

\footnotetext{
Received Nov. 14, 2002; revised Dec. 26, 2002; accepted Dec. 31, 2002.

This work was supported by United States Public Health Service Grants AA10760 (A.E.R., F.O.R., T.J.P.), AA13331 (T.J.P.), AA13483 (N.J.G.), and AA13223 (R.K.B.), a grant from the Department of Veteran Affairs (T.J.P.), and a fellowship from Consejo Nacional de Ciencia y Tecnologia-Mexico (A.G.R.).

Correspondence should be addressed to Dr. Andrey E. Ryabinin, Department of Behavioral Neuroscience, L470, Oregon Health and Science University, 3181 Southwest Sam Jackson Park Road, Portland, OR 97239. E-mail: ryabinin@ohsu.edu.

Copyright $\odot 2003$ Society for Neuroscience $\quad 0270-6474 / 03 / 232477-11 \$ 15.00 / 0$
}

animals may differ from alcohol-avoiding animals, it is important to characterize the neural systems of animals predisposed to low alcohol consumption. C57BL/6 (B6) and DBA/2 (D2) inbred mouse strains provide ideal models for identifying the neural systems involved in predispositions toward increased alcohol drinking or protection against extreme alcohol intake in that B6 mice voluntarily drink copious amounts of alcohol, whereas D2 mice drink very little alcohol (McClearn and Rodgers, 1959; Belknap et al., 1993). The first goal of the present study was to identify and compare the neural systems in B6 and D2 mice voluntarily consuming alcohol using c-Fos immunohistochemistry.

The results of this c-Fos mapping in alcohol-consuming B6 and D2 mice point to urocortin (Ucn) cells within the EdingerWestphal nucleus (EW) and its major forebrain target, the lateral septum (LS), as important sites of action (Bittencourt et al., 1999). The EW has received recent attention given its unique sensitivity to both voluntary and involuntary administration of alcohol (Chang et al., 1995; Bachtell et al., 1999; Ryabinin et al., 2001; Weitemier et al., 2001). The EW is also the primary source of the neuropeptide Ucn, which is structurally and functionally similar to corticotropin-releasing factor (CRF) (Vaughan et al., 1995; Reyes et al., 2001). Interestingly, a recent report shows that B6 mice possess significantly higher Ucn-positive cells in the EW than D2 mice (Bachtell et al., 2002). Therefore, our second goal was to characterize the B6/D2 distinction in the LS component of the EW-LS Ucn pathway.

Finally, our third goal was to test the hypothesis that B6 and 
D2 strain differences in the EW-LS Ucn pathway contribute to their divergent alcohol consumption tendencies. Thus, we analyzed the EW-LS Ucn pathway and correlated Ucn expression measures with alcohol consumption on two voluntary drinking paradigms in B6D2 F2 mice. Confirmation of these results was achieved by analyzing the Ucn pathway of an alcohol-avoiding congenic mouse line and mouse lines selectively bred for differences in alcohol preference.

\section{Materials and Methods}

Subjects. All animal procedures followed the Guide for the Care and Use of Laboratory Animals (NIH publication No. 85-23, revised 1996). For the c-Fos mapping experiment, 7-week-old male B6 and D2 mice ( $n=30$ per strain) were purchased from The Jackson Laboratory (Bar Harbor, ME) and housed four per cage on a $12 \mathrm{hr} \mathrm{light/dark} \mathrm{cycle} \mathrm{(lights} \mathrm{off} \mathrm{at} 6$ P.M.). There was ad libitum access to food (LabDiet 5001) at all times. At 1 week after arrival, animals were housed individually in metal hanging racks and exposed to the limited-access ethanol/sucrose drinking procedure outlined below. A separate set of male B6 and D2 mice (age 7-8 weeks; $n=4$ per strain) were used for quantification of $\mathrm{Ucn}$ processes in the LS. These mice were purchased from The Jackson Laboratory, housed four per cage, and maintained with ad libitum food and water until they were killed.

The B6D2 F2 intercross population of mice was generously provided by J. K. Belknap (Oregon Health and Science University, Portland, OR). Ten B6D2 F2 litters $(n=85$ mice; male $=42$, female $=43)$ were generated from 10 pairs of B6D2 F1 breeders. At 8-9 weeks of age, all B6D2 F2 mice were housed individually and run through the two-bottle choice and the limited-access alcohol/sucrose drinking procedures outlined below.

The B6.D2 Alcp1 Line 2.2 congenic mice were originally generated by Whatley and colleagues (1999) at the Institute for Behavioral Genetics (University of Colorado, Boulder, CO). The population used in the present studies was bred and maintained at the Portland Alcohol Research Center Core at the Veterans Affairs Medical Center (Portland, OR). Group-housed (three to five per cage) males and females from the B6.B6 control strain $($ males $=15$; females $=12$ ) and B6.D2 Alcp1 Line 2.2 congenic strain $($ males $=13$; females $=11)$ were used for Ucn analysis. Mice were 7-9 weeks old at the time they were killed.

High alcohol-preferring (HAP) and low alcohol-preferring (LAP) selected line mice were generated and housed at the Indiana University Department of Psychiatry (Grahame et al., 1999). HAP/LAP mice generated from two replicate lines were used. HAP/LAP mice from replicate line 1 were taken from generation $22(\mathrm{HAP}$ male $=8 ; \mathrm{LAP}$ male $=8 ; \mathrm{HAP}$ female $=7$; LAP female $=8$ ), and HAP/LAP mice from replicate line 2 were taken from generation $13(\mathrm{HAP}$ male $=8$; LAP male $=7$; HAP female $=8$; LAP female $=8$ ). Mice were 7-9 weeks old when they were killed.

Alcohol drinking procedures in B6 and D2 mice for c-Fos immunohistochemistry. A limited-access ethanol/sucrose drinking procedure was used with the intent of maximizing and stabilizing alcohol intake (Grant and Samson, 1985; Bachtell et al., 1999; Ryabinin et al., 1999). After 1 week of habituation to the individual housing conditions, animals were waterdeprived for $22 \mathrm{hr}$ and then given access to a $20 \%$ sucrose solution for 2 hr (9:00-11:00 A.M.). Fluids were presented in $25 \mathrm{ml}$ graduated glass cylinders that were fitted with stainless steel drinking spouts and inserted through the front of the cage. This day was designated as day 0 . During the next $10 \mathrm{~d}$, access to sucrose was gradually decreased from $2 \mathrm{hr}$ to 30 $\mathrm{min}$, and access to water was increased from 0 to $20 \mathrm{hr}$. On day 11, the sucrose solution was changed to $10 \%$. Beginning with this day, the schedule of access to drinking solutions and procedure remained constant: access to tap water was from 10:00 A.M. to 8:00 A.M.; from 8:00 to 9:00 A.M., bottles were removed and body weight was measured; from 9:00 to 9:30 A.M., mice had access to the test solutions. During days 12-28, 20 subjects (sucrose group; 10 per strain) continued to receive the $10 \%$ sucrose solution. In another 20 animals (ethanol/sucrose group; 10 per strain), ethanol was gradually added to the $10 \%$ sucrose solution at increasing concentrations from $0 \%$ (on day 12 ) to $2 \%(\mathrm{v} / \mathrm{v}$, during days
$13-14)$ to $5 \%$ for the remainder of the experiment (days 15-28). A separate group of 20 animals was treated identically to the sucrose and ethanol/sucrose group except that they ingested only tap water (water group; 10 per strain) throughout the study. At 60-100 min after the last drinking session, mice were given an overdose of $\mathrm{CO}_{2}$, and brains were rapidly extracted in an adjacent room for c-Fos immunohistochemistry. The time that they were killed was selected because c-Fos expression peaks after most types of neuronal stimulation at this interval (Morgan and Curran, 1991). They were killed individually with a 30-45 sec interval between each mouse. All animals were killed on the same day. Trunk blood was collected at this time for blood ethanol concentration (BEC) analysis.

Alcohol drinking procedures for the B6D2 F2 intercross experiment. Data were collected from two cohorts of B6D2 F2 mice (cohort 1, $n=37$; cohort 2, $n=48$ ). Both cohorts were exposed to a two-bottle drinking procedure followed by a limited-access drinking procedure. To control for possible Ucn expression changes produced by exposure to ethanol, 10 control subjects were included in cohort 2 that received no ethanol at any time during the two procedures. The experiment was initiated when animals were individually housed in metal hanging racks. On the first through the fourth day of the experiment, animals were given continuous access ( $24 \mathrm{hr}$ ) to two $25 \mathrm{ml}$ cylinders (one containing tap water and one containing $3 \%$ ethanol in tap water). On the 5th through 8 th and 9th through 12th day of the experiment, the ethanol concentration was 6 and $10 \%$, respectively. Control animals from cohort 2 received two bottles of tap water throughout the experiment. Body weights and fluid consumption (tenths of milliliters) from both cylinders were recorded daily at 8 A.M. (1 hr after light onset). Bottle positions were alternated daily to avoid development of a position preference. Both preference measures (milliliters of alcohol consumed/milliliters of total fluid consumed) and consumption measures (grams per kilogram per day) were calculated and used as dependent variables. Mice were then given a $4 \mathrm{~d}$ break from ethanol, at which time only one bottle of tap water was provided $24 \mathrm{hr} / \mathrm{d}$. On the fifth day after the end of the two-bottle procedure, animals were exposed to a limited access ethanol/sucrose drinking procedure. Mice were initiated into the procedure with a $22 \mathrm{hr}$ water deprivation phase. They were then allowed access to a $20 \%$ sucrose solution for $2 \mathrm{hr}$. This was designated as day 1 . During the next $3 \mathrm{~d}$, access to the sucrose solution was gradually decreased from $2 \mathrm{hr}$ to $30 \mathrm{~min}$, and access to water was increased from 0 to $20 \mathrm{hr}$. On the fifth day, the sucrose solution was changed to $10 \%$. Starting on this day, the schedule of access to drinking solution and procedures was maintained as follows: access to tap water was from 10:00 A.M. to 8:00 A.M.; from 8:00 to 9:00 A.M., bottles were removed and body weight was measured; from 9:00 to 9:30 A.M., mice had access to the test solutions. Ethanol was then gradually added to the sucrose solution at increasing concentrations (3, 6, and 10\%) for $3 \mathrm{~d}$ each. The control animals in cohort 2 were maintained on a $10 \%$ sucrose solution during the $30 \mathrm{~min}$ access session. Mice were killed by cervical dislocation, and brains were extracted 30-32 hr after the final drinking session. Mice in this experiment were not overdosed with $\mathrm{CO}_{2}$ because of the necessity to process many animals in a short amount of time and the potential for $\mathrm{CO}_{2}$ exposure to alter Ucn levels. Ucn immunohistochemistry was performed as outlined below.

c-Fos immunohistochemistry. Immunohistochemistry was performed according to previous protocols (Bachtell et al., 2002). Briefly, dissected brains were postfixed overnight in $2 \%$ paraformaldehyde in isotonic sodium PBS and cryoprotected with 30\% sucrose in PBS. Frozen coronal sections $(40 \mu \mathrm{m})$ were collected in PBS from bregma level 1.70 to -4.24 $\mathrm{mm}$ according to the mouse brain atlas (Franklin and Paxinos, 1997). Immunohistochemical analysis for c-Fos was performed on every fifth section from approximate bregma levels of 1.1 to $-3.9 \mathrm{~mm}$ ( 25 sections per animal). Endogenous peroxidase activity was inhibited by pretreatment with $0.3 \%$ hydrogen peroxide. Blocking was performed with $6 \%$ goat serum. Rabbit polyclonal antibodies against amino acids $210-335$ of human c-Fos protein that are not cross-reactive with FosB, Fra-1, and Fra-2 (Santa Cruz Biotechnology, Santa Cruz, CA) were used in a dilution of 1:10,000. The immunoreaction was detected with Vectastain ABC kit (Vector Laboratories, Burlingame, CA). Enzymatic development was performed with the Metal Enhanced DAB kit (Pierce, Rockford, IL). 
Ucn immunohistochemistry. Ucn immunohistochemistry was performed according to previously published protocols (Bachtell et al., 2002). Briefly, brains were postfixed in $2 \%$ paraformaldehyde in PBS and cryoprotected with $30 \%$ sucrose in PBS, and immunohistochemistry was performed on $40 \mu \mathrm{m}$ floating slices. Endogenous peroxidase activity was quenched by $0.3 \%$ peroxide in PBS. Blocking was performed with $4 \%$ horse serum. A goat polyclonal antibody against an epitope at the $\mathrm{C}$ terminus of rat Ucn (Santa Cruz Biotechnology) was used at a dilution of 1:10,000. Biotinylated anti-goat secondary antibody was used to detect the primary antibody (Vector Laboratories). The immunoreaction was detected with the Vectastain $\mathrm{ABC}$ kit (Vector Laboratories), and enzymatic development was accomplished with the Metal Enhanced DAB kit (Pierce). Ucn-positive cells were topographically identified as EW according to the brain atlas (Franklin and Paxinos, 1997). However, the identity of peptidergic neurons in the EW proper with cells projecting to the ciliary ganglion in non-primate mammals remains to be determined (Erichsen and May, 2002).

Analysis of Ucn processes in the septum was performed using a modified immunohistochemistry protocol. Animals were perfused transcardially with $4 \%$ paraformaldehyde (with the exception of B6D2 F2 mice and HAP/LAP, which were only postfixed). Brains were then postfixed for $24 \mathrm{hr}$ in the same solution and cryoprotected with $30 \%$ sucrose. Forty micrometer sections containing the LS $(\sim 15$ from each animal $)$ and the EW were selected for immunohistochemical processing. Sections were incubated for $5 \mathrm{hr}$ in a blocking solution containing $2 \%$ BSA and $1 \mathrm{mg} / \mathrm{ml}$ heparin. After blocking, sections were incubated overnight in rabbit antiUcn antibody corresponding to amino acids $105-120$ of human pro-Ucn (Sigma, St. Louis, MO). Biotinylated anti-rabbit secondary antibody was used to detect the primary antibody (Vector Laboratories). The immunoreaction was detected using the Vectastain $\mathrm{ABC}$ kit, and enzymatic development was accomplished with the Metal Enhanced DAB kit. To assess the specificity of positive staining in the LS, several brain sections from B6 and D2 mice were incubated in primary antibody that was previously incubated for $12 \mathrm{hr}$ in $100 \mu \mathrm{mol}$ of rat Ucn, mouse Ucn II, mouse Ucn III, or rat CRF peptide (Phoenix Pharmaceuticals Belmont, CA).

Double immunohistochemistry. Double immunohistochemistry was performed as described previously (Bachtell et al., 2002; Ryabinin et al., 2003). Briefly, procedures were initiated as described above for c-Fos immunohistochemistry with the exception that $4 \%$ horse serum was used for blocking. After the first reaction (c-Fos) and DAB staining, unbound avidin and biotin resulting from initial reactions were blocked using the Avidin/Biotin Blocking kit (Vector Laboratories). Sections were then incubated for $4 \mathrm{hr}$ in $4 \%$ horse serum, followed by incubation with the goat anti-Ucn primary antibody at a dilution of 1:10,000. The immunoreaction was detected with the Vectastain ABC kit as above, whereas enzymatic development was performed with the Vector VIP staining kit (Vector Laboratories). To confirm specificity of the staining, parallel sections were taken through the identical procedure with omission of either the c-Fos- or the Ucn-specific antibodies.

Blood ethanol measurements. After trunk blood was collected from killed animals, BECs were determined by the spectrophotometric NADADH Detection System (Sigma). Nicotinamide adenine dinucleotide (NAD)-alcohol dehydrogenase (ADH) reactivity was measured in $3 \mu \mathrm{l}$ blood samples from individual animals.

Data analysis. Drinking data in the c-Fos mapping study were analyzed by a mixed design three-way ANOVA. Days (final $16 \mathrm{~d}$ ) were used as a within-subjects variable, and strain (B6 or D2) and group (sucrose, ethanol/sucrose, or water) served as the between-groups variables. Only the final $16 \mathrm{~d}$ of the procedure were used in the analysis because there was considerable manipulation of the procedure during the first $15 \mathrm{~d}$ (e.g., fluid deprivation and varying access session lengths). Additionally, the final $16 \mathrm{~d}$ represent the days in which alcohol was introduced into the $10 \%$ sucrose in the ethanol/sucrose group. Significant interactions were analyzed with post hoc Fisher's PLSD tests.

Quantitative image analysis for c-Fos and Ucn immunohistochemistry was performed using a system consisting of an Olympus microscope BX40 and Sony CCD IRIS/RGB video camera connected to a Power PC. Each digitized video image was analyzed using NIH Image 1.62 software. Nuclear c-Fos labeling was detected using a threshold normalization procedure, in which neighboring areas with no immunoreactivity were adjusted to contain no positive signals. Remaining grains in a size range from 7 to 50 pixels were counted automatically. All counting was performed by the same individual, who was blind to the experimental group of the analyzed animal. The value for a single matched region was summed for each bilateral area and used as a single data point for statistical analysis using a one-way ANOVA. Control for variations in brain area size were made on the basis of careful slice selection, with strong consideration of their location as detailed by Franklin and Paxinos (1997). It is believed that this methodology controls for issues in cell counting and is thus an unbiased method (Saper, 1996). For analysis of some brain regions, we were not able to match sections from all 30 animals to the same location. In such situations, counts in this brain region for this animal were not performed. Therefore, the actual numbers of animals per group analyzed for c-Fos expression were 7-10.

Ucn-positive cells in EW ( -3.20 to $-3.60 \mathrm{~mm}$ from bregma) and Ucn-positive processes in LS $(+1.2$ to $+0.3 \mathrm{~mm}$ from bregma) were counted manually by an experimenter blind to the experimental conditions, because of the inability of the software to present accurate counts of
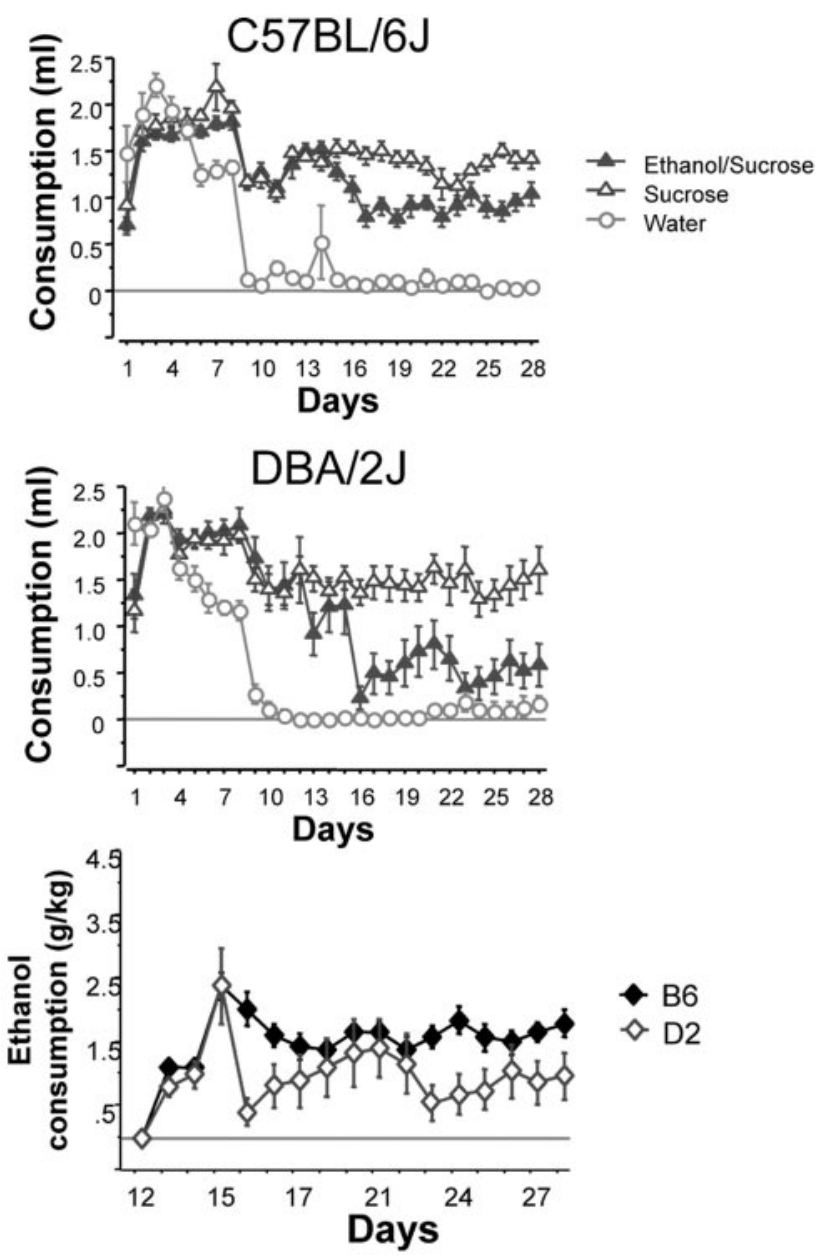

Figure 1. Consumption patterns of D2 (top) and B6 (middle) mice during the entire 30 min limited access procedure. On days 1-10, fluid access times were gradually decreased from $2 \mathrm{hr}$ to 30 min during the test session. These changes were concurrent with gradual decreases in overall fluid deprivation ( $22 \mathrm{hr}$ to $2 \mathrm{hr}$ without access to fluid). On day 11, all mice except the water group were given $10 \%$ sucrose for 30 min. Alcohol was first introduced on day 13 at a $2 \%$ concentration in $10 \%$ sucrose, which was subsequently increased to $5 \%$ ethanol in $10 \%$ sucrose on day 15. Analysis of the significant group $\times$ strain interaction reveals differences between the strains in consumption levels of the ethanol/sucrose group $(p<0.001)$, but not sucrose or water. The bottom panel shows a strain comparison of ethanol consumption (grams per kilogram) during the $30 \mathrm{~min}$ limited access session. As expected, B6 mice consume more ethanol that $\mathrm{D} 2$ mice $(p<0.001)$. 
Table 1. c-Fos expression in mice after limited access to test solutions

\begin{tabular}{|c|c|c|c|c|c|c|c|}
\hline & B6 Strain & & & D2 Strain & & & \\
\hline & Water & Sucrose & Ethanol/sucrose & Water & Sucrose & Ethanol/sucrose & ANOVA \\
\hline Hippocar & & & & & & & \\
\hline DG & $5.0 \pm 1.1$ & $6.1 \pm 1.0$ & $4.5 \pm 0.8$ & $8 \pm 1.3$ & $12.5 \pm 7.2$ & $6.2 \pm 0.9$ & \\
\hline CA1 & $0.3 \pm 0.1$ & $1.1 \pm 0.6$ & $0.2 \pm 0.1$ & $0.3 \pm 0.2$ & $0.3 \pm 0.2$ & $0.3 \pm 0.2$ & \\
\hline $\mathrm{CA} 2$ & $0 \pm 0$ & $0 \pm 0$ & $0.1 \pm 0.1$ & $0 \pm 0$ & $0.4 \pm 0.2$ & $0.4 \pm 0.4$ & \\
\hline CA3 & $2.0 \pm 0.7$ & $1.5 \pm 0.4$ & $2.2 \pm 1.0$ & $1.3 \pm 0.7^{a}$ & $3.7 \pm 0.8$ & $1.1 \pm 0.4^{a}$ & GXS \\
\hline Septum & & & & & & & \\
\hline$A c b C$ & $0.1 \pm 0.1$ & $0.3 \pm 0.2$ & $0.1 \pm 0.1$ & $0.1 \pm 0.1$ & $0.4 \pm 0.2$ & $0.4 \pm 0.2$ & \\
\hline AcbS & $0.9 \pm 0.4$ & $1.5 \pm 0.3$ & $1.3 \pm 0.3$ & $1.6 \pm 0.2$ & $1.9 \pm 0.4$ & $1.6 \pm 0.3$ & \\
\hline BNST & $2.8 \pm 0.5$ & $3.4 \pm 0.9$ & $2.8 \pm 0.6$ & $3.3 \pm 0.8$ & $3.3 \pm 0.9$ & $2.0 \pm 0.8$ & \\
\hline LSd & $2.0 \pm 0.3$ & $2.6 \pm 0.5$ & $1.4 \pm 0.6$ & $1.0 \pm 0.3$ & $2.7 \pm 0.5$ & $1.6 \pm 0.4$ & G \\
\hline $\mathrm{LSi}$ & $1.9 \pm 0.5$ & $2.3 \pm 0.3$ & $1.0 \pm 0.2^{a}$ & $0.9 \pm 0.4$ & $2.2 \pm 0.4^{b}$ & $2.0 \pm 0.3^{b}$ & $G, G \times S$ \\
\hline LSv & $1.4 \pm 0.2$ & $1.7 \pm 0.5$ & $0.8 \pm 0.3$ & $1.3 \pm 0.5$ & $1.4 \pm 0.4$ & $1.5 \pm 0.5$ & \\
\hline MS & $1.6 \pm 0.4$ & $2.0 \pm 0.5$ & $1.4 \pm 0.4$ & $1.3 \pm 0.3$ & $1.2 \pm 0.4$ & $0.5 \pm 0.2$ & $S$ \\
\hline Amygdal & & & & & & & \\
\hline La & $0 \pm 0$ & $0.1 \pm 0.1$ & $0.1 \pm 0.1$ & $0 \pm 0$ & $0 \pm 0$ & $0.4 \pm 0.1$ & \\
\hline BLA & $1.0 \pm 0.5$ & $1.8 \pm 0.5$ & $1.7 \pm 0.7$ & $0.4 \pm 0.2$ & $1.6 \pm 0.7$ & $0.9 \pm 0.4$ & \\
\hline CeM & $1.3 \pm 0.6$ & $1.1 \pm 0.5$ & $1.7 \pm 0.7$ & $1.7 \pm 0.5$ & $2.6 \pm 0.6$ & $2.7 \pm 0.8$ & \\
\hline Cel & $0.7 \pm 0.4$ & $1.6 \pm 0.6$ & $2.0 \pm 0.6$ & $0.9 \pm 0.5$ & $1.2 \pm 0.6$ & $1.7 \pm 0.7$ & \\
\hline Hypotha & & & & & & & \\
\hline AHP & $6.8 \pm 1.4$ & $5.7 \pm 1.4$ & $5.8 \pm 1.6$ & $2.8 \pm 1.7$ & $7.3 \pm 3.8$ & $1.1 \pm 0.5$ & \\
\hline $\mathrm{LH}$ & $1.8 \pm 0.8$ & $1.3 \pm 0.5$ & $0.6 \pm 0.3$ & $0.9 \pm 0.3$ & $2.9 \pm 0.8$ & $1.1 \pm 0.8$ & \\
\hline $\mathrm{Pa}$ & $9.0 \pm 4.3$ & $4.8 \pm 1.4$ & $9.0 \pm 2.8$ & $2.8 \pm 1.2$ & $2.1 \pm 0.6$ & $3.7 \pm 3.0$ & $S$ \\
\hline PV & $13.7 \pm 5.1$ & $7.0 \pm 1.2$ & $12.0 \pm 3.5$ & $20.1 \pm 5.3$ & $35.7 \pm 6.7$ & $22.9 \pm 5.8$ & $S^{* *}$ \\
\hline SO & $1.6 \pm 0.4$ & $0.9 \pm 0.3$ & $0.9 \pm 0.3$ & $1.7 \pm 0.2$ & $1.0 \pm 0.4$ & $1.7 \pm 0.6$ & \\
\hline Neocorte & & & & & & & \\
\hline M & $0.4 \pm 0.3$ & $0.4 \pm 0.2$ & $0.2 \pm 0.1$ & $0.3 \pm 0.2$ & $0.1 \pm 0.1$ & $0.2 \pm 0.2$ & \\
\hline Pir & $3.9 \pm 0.6$ & $5.3 \pm 0.7$ & $5.1 \pm 1.3$ & $5.4 \pm 1.0$ & $6.7 \pm 1.2$ & $3.7 \pm 0.7$ & \\
\hline RS & $0.3 \pm 0.2$ & $0.2 \pm 0.1$ & $0 \pm 0$ & $0.1 \pm 0.1$ & $0.6 \pm 0.2$ & $1.5 \pm 1.1$ & \\
\hline S1 & $0.3 \pm 0.2$ & $0.3 \pm 0.2$ & $0.3 \pm 0.2$ & $0.3 \pm 0.2$ & $0.4 \pm 0.2$ & $0.3 \pm 0.2$ & \\
\hline Midbrain & & & & & & & \\
\hline EW & $6.8 \pm 1.2$ & $10.4 \pm 1.7$ & $17.9 \pm 1.9$ & $3.7 \pm 1.0$ & $4.8 \pm 0.8$ & $7.4 \pm 3.2$ & $\mathrm{G}^{* *}, \mathrm{~S}^{* *}$ \\
\hline VTA & $0.6 \pm 0.2$ & $0.4 \pm 0.2$ & $0.4 \pm 0.2$ & $0.6 \pm 0.3$ & $0.2 \pm 0.1$ & $0.3 \pm 0.2$ & \\
\hline
\end{tabular}

Data are presented as mean \pm SEM. AcbC, Core of nucleus accumbens $(+1.1 \mathrm{~mm}) ; \mathrm{AcbS}$, shell of nucleus accumbens $(+1.1 \mathrm{~mm}) ;$ AHP, posterior portion of anterior hypothalamus $(-1.22 \mathrm{~mm}) ; B L A$, basolateral amygdala $(-1.2 \mathrm{~mm}) ; \mathrm{BNST}$ bed nucleus of stria terminalis $(+0.5 \mathrm{~mm}) ; \mathrm{CA} 1(-1.5 \mathrm{~mm}) ; \mathrm{CA2}(-1.5 \mathrm{~mm}) ; \mathrm{CA3}(-1.5 \mathrm{~mm})$; CeL and CeM, capsular, lateral, and medial divisions of central nucleus of amygdala $(-1.2 \mathrm{~mm}) ; \mathrm{DG}$, dentate gyrus $(-1.5 \mathrm{~mm})$; EW, Edinger-Westphal nucleus $(-3.8 \mathrm{~mm})$; LH, lateral hypothalamus $(-0.9 \mathrm{~mm}) ; \mathrm{LSD}, \mathrm{LSI}$, and LSV, lateral septum dorsal, intermediate, and ventral $(+0.7 \mathrm{~mm}) ; \mathrm{M}$, motor cortex $(-1.2 \mathrm{~mm})$; $M$, medial septum $(+0.7 \mathrm{~mm}) ;$ Pa, paraventricular nucleus of hypothalamus $(-0.9 \mathrm{~mm}) ; \mathrm{PH}$, posterior hypothalamus $(-2.5 \mathrm{~mm})$; Pir, piriform cortex $(-1.2 \mathrm{~mm}) ; \mathrm{PV}$, paraventricular nucleus of thalamus $(-0.9 \mathrm{~mm}) ; \mathrm{RS}$, retrosplenial agranular cortex $(-1.2 \mathrm{~mm}) ; \mathrm{S} 1$, somatosensory cortex $(-1.2 \mathrm{~mm})$; VTA, ventral tegmental area $(-3.5 \mathrm{~mm})$; ANOVA: $G$, significant effect of group; S, significant effect of strain; GXS, significant group by strain interaction, $p<0.05$.

${ }^{* *} p<0.001$

${ }^{a}$ Fisher's post hoc comparisons for brain areas with significant interactions. Significantly different from sucrose group of same strain.

${ }^{b}$ Fisher's post hoc comparisons for brain areas with significant interactions. Significantly different from water group of same strain.

overlapping cells and the disparate locations of Ucn-positive processes. Ucn-positive processes that were counted appeared as beaded varicosities. One varicosity, regardless of length, was counted as one Ucn process and summed for each LS-containing section. Colocalization was also assessed manually by counting c-Fos-positive nuclei, Ucn-containing cells, and the occurrence of c-Fos-positive nuclei localized within Ucn-containing cells. Ucn expression measures were performed using an automated system on the NIH Image 1.62 software. Each digitized image was adjusted for equal background by subtracting out noise signals. Each image was calibrated according to a standard optical density curve. The average optical density was then generated and recorded. Measurements of the number of Ucn cells per brain slice and optical density of Ucn in EW were performed on three to eight sections per animal and averaged for each animal, providing a single data point per animal used in the ANOVA. Assessments of Ucn in LS were made on 15 sections per animal, which were summed to create a single data point per animal used in the ANOVA. Because of differences in staining intensity among immunohistochemical reactions, exact measures of immunoreactivity were not compared between experiments. Therefore, all statistical comparisons were made only on sections processed simultaneously. Differences between individual groups were evaluated post hoc using the Fisher's test. Effects with $p<0.05$ were considered statistically significant.

\section{Results}

\section{Alcohol consumption patterns of $\mathrm{B} 6$ and $\mathrm{D} 2$ mice}

Analysis of consumption patterns of B6 and D2 mice over days in the sucrose, ethanol/sucrose, and water groups during the limited access procedure using a three-way ANOVA revealed significant main effects of group $\left(F_{(2,756)}=685.66 ; p<0.001\right)$, strain $\left(F_{(1,756)}=10.26 ; p<0.005\right)$, and group $\times$ strain interaction $\left(F_{(2,756)}=20.732 ; p<0.001\right)$ (Fig. 1). Consumption patterns over the final $16 \mathrm{~d}$ remained stable as revealed by no significant main or interactive effects of the day variable. Because no effects were observed with the day variable, all post hoc comparisons were made collapsed across days. Thus, subsequent analysis of the group $\times$ strain interaction using a Fisher's PLSD test revealed that, as expected, B6 mice consumed significantly more ethanol/ sucrose than D2 mice $(p<0.001)$, whereas no strain differences were observed in the consumption of sucrose $(p=0.17)$ or water $(p=0.94)$. Of note, however, on the final day of the procedure, B6 and D2 mice consumed physiologically relevant levels of ethanol/sucrose, reaching doses of $1.75 \pm 0.21$ and $0.98 \pm 0.37$ $\mathrm{gm} / \mathrm{kg}$, respectively, and BECs of $97.4 \pm 17.4$ and $67.1 \pm 13.5$ $\mathrm{mg} \%$, respectively. Although ethanol consumption between the strains differed, the consumption of ethanol in both strains on 


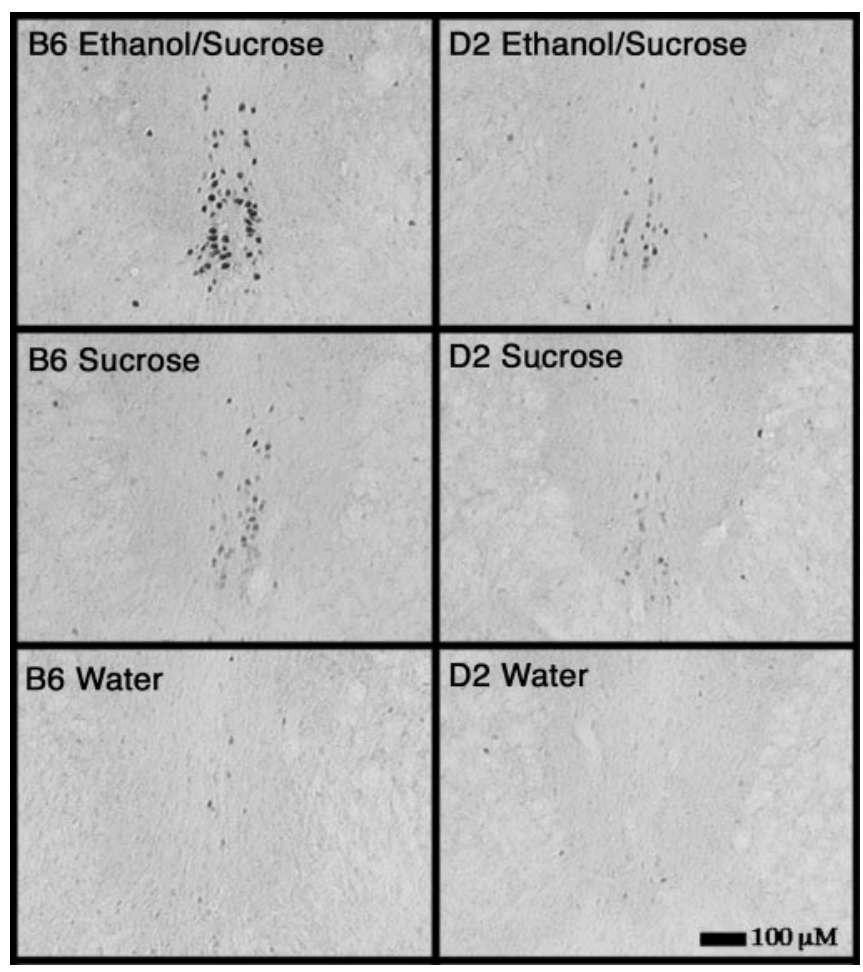

Figure 2. Consumption of the ethanol/sucrose solution significantly elevates c-Fos expression in the $\mathrm{EW}$ in $\mathrm{B} 6$ and D2 mice. Induction was significantly lower in the D2 versus the B6 strain.

the day they were killed allowed us to evaluate and compare c-Fos immunohistochemistry throughout the brain of both strains.

\section{Induction of c-Fos expression after voluntary alcohol consumption in $\mathrm{B} 6$ and $\mathrm{D} 2$ mice}

Analysis of 26 brain regions confirmed results of previous studies suggesting that only a small subset of brain regions show altered c-Fos expression after ethanol drinking (Table 1). Only the EW showed a robust increase in c-Fos expression after ethanol/sucrose drinking (Fig. 2). Post hoc Fisher's PLSD comparisons confirmed that there was a significant difference in c-Fos expression between the ethanol/sucrose group and the sucrose group $(p<0.02)$ and the water group $(p<0.001)$ in both strains. Regardless of fluid consumed, B6 mice had significantly higher levels of c-Fos expression than D2 mice. Using double immunohistochemistry it was observed that ethanol-induced expression of c-Fos in EW of both strains occurred nearly exclusively in Ucn-expressing cells (B6 $=92.29 \pm$ $4.20 \%$ and $\left.\mathrm{D} 2=79.18 \pm 7.50 \% ; F_{(1,8)}<1, \mathrm{NS}\right)$.

More complex c-Fos expression patterns were identified in the lateral septum and the hippocampus. Significant interactions between effects of group and strain on c-Fos expression were observed in the intermediate portion of the lateral septum and in the $\mathrm{CA} 3$ region of the hippocampus. These may be attributable to differences in doses of ethanol consumed by D2 and B6 mice. Notably, however, this is not the case for the dorsal portion of the lateral septum, where the difference between groups was caused by higher expression of c-Fos in the sucrose group versus the ethanol/sucrose and the water groups (Fisher's PLSD; $p<0.02$ ).

\section{Characterization of lateral septum Ucn processes in $\mathrm{B} 6$ and D2 mice}

We have shown previously that B6 and D2 mice differ in the number of cells expressing Ucn in the EW (Bachtell et al., 2002). This difference, combined with the present finding that con- sumption of sucrose and ethanol/sucrose regulated c-Fos expression in the LS in a complicated manner that appeared genotypedependent, warrants a more detailed characterization of the EW-LS Ucn pathway in B6 and D2 mice. Thus, we compared Ucn immunoreactivity in the LS of B6 and D2 mice (Fig. 3). In agreement with studies performed in rats (Bittencourt et al., 1999), we observed Ucn-positive processes in the LS of both strains of mice. The observed immunoreactivity is consistent with reports in other species highlighting $U_{c n}$ processes in the septum of non-colchicine-treated animals (Kozicz et al., 2002). Specificity of the Ucn-positive immunoreactivity was confirmed by abolishing Ucn-positive immunoreactivity after preincubation of the primary antibody with $100 \mu \mathrm{M} \mathrm{Ucn}$. Ucn-positive immunoreactivity was unaffected by primary antibody preincubation with $100 \mu \mathrm{M}$ Ucn II, Ucn III, or CRF. Quantification of these processes showed that the highest level of Ucn-positive immunoreactivity in both strains was in the intermediate medial portion. This coincides with the septal region displaying the greatest density of corticotropin-releasing hormone receptor 2 (CRHR2) receptors and the prominent target region for Ucn forebrain projections (Skelton et al., 2000). It is therefore believed that the immunoreactivity observed here represents Ucn projections targeting CRHR2 receptors in this region. A mixeddesign two-way ANOVA was used to analyze strain (between) and subregion (within) differences in Ucn processes. Contrary to our expectations, the main effect of strain revealed a higher number of Ucn processes in the $\mathrm{D} 2$ strain compared with the $\mathrm{B} 6$ strain $\left(F_{(1,120)}=16.09 ; p<0.001\right)$. No interaction of the septal subregion and strain was observed $(p>0.05)$. This finding is a replication of pilot experiments with separate populations of mice $(n=7$ per strain).

\section{Alcohol consumption patterns in the $\mathrm{B} 6 \mathrm{D} 2 \mathrm{~F} 2$ intercross mice and the relationship to the Edinger-Westphal-lateral septum Ucn pathway}

If indeed the EW-LS Ucn pathway is involved with alcohol consumption, it could be hypothesized that parallel differences between Ucn measures and alcohol consumption in a heterogeneous population of mice would exist. To this aim, we obtained several distributions of data representing consumption and preference measures of B6D2 F2 mice (Fig. 4). Using these data sets, we generated correlation coefficients for consumption and preference, the number and density of Ucn-expressing cells in EW, and the number of Ucn processes in the LS (Table 2). Ucn expression, number of Ucn-positive cells in EW, and number of Ucn-positive processes in the LS were significantly correlated with consumption of $10 \%$ ethanol in the 30 min limited access drinking procedure. However, there were no significant correlations with consumption or preference from the continuous access study. The results of these analyses present suggestive evidence for a relationship between high ethanol consumption and low LS Ucn process number and high EW Ucn cell number and density in a situation in which a high dose of ethanol is consumed in a short time period. They may also provide a physiological explanation for the differential ethanol consumption levels seen in B6 and D2 mice.

The implementation of the control group, which consumed no ethanol throughout the continuous access and limited-access procedures, enabled us to reveal potential regulatory effects of Ucn in the EW and septum after long-term ethanol consumption (Fig. 5). Analysis of ethanol-drinking mice and control mice of cohort 2 showed no regulation in the number of EW Ucn cells or density by ethanol consumption $\left(F_{(1,35)}<1\right.$, NS, and $F_{(1,35)}<1$, NS, respectively). Analysis of the Ucn-containing LS processes, however, dem- 

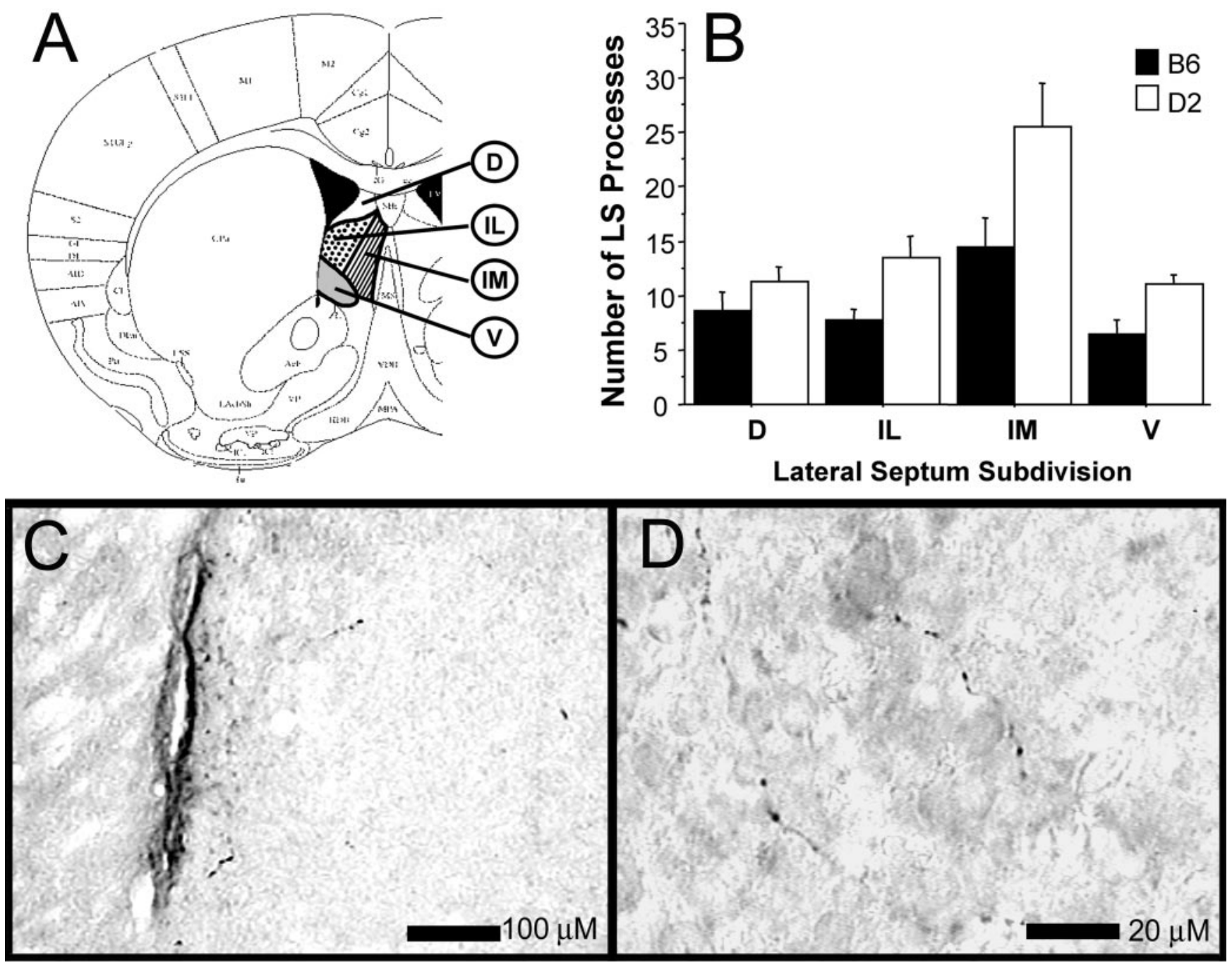

Figure 3. The following four subregions ( $A$ ) of the lateral septum were analyzed and compared between the $B 6$ and $D 2$ strains: $D$, dorsal; $V$, ventral; $I M$, intermediate medial; $I L$, intermediate lateral. Statistical analysis of $U \mathrm{cn}$ processes in the $\mathrm{LS}$ of $\mathrm{B} 6$ and $\mathrm{D} 2$ mice revealed a significant main effect of strain, in which D2 mice have higher numbers of processes than $B 6$ mice $(B)$. Note the architectural nature of the $U c n-$ positive processes in $L S$ at $100 \times(C)$ and $1000 \times(D)$ magnification.

onstrated that ethanol-consuming mice had significantly lower numbers of Ucn processes in the LS $\left(F_{(1,32)}=17.35 ; p<0.001\right)$.

Expression of Ucn in Edinger-Westphal of B6.D2 Alcp1 congenic mice conferring an alcohol avoidance phenotype To confirm the importance of EW Ucn in the drinking behaviors of B6 and D2 mice, we obtained a B6 congenic mouse strain carrying a D2 chromosomal segment including Alcp1. A D2 allele at this locus has been shown to reduce alcohol consumption in B6 mice in a primed free-choice paradigm (Whatley et al., 1999). The congenic strain, B6.D2 Alcp1, was created using classical backcross procedures to introduce D2 alleles onto a B6 background while selecting for D2-like (alcohol avoidance) drinking patterns (Whatley et al., 1999). Importantly, the phenotype conferred by B6.D2 Alcp1 mice is sex specific in that only males possess the D2-like alcohol avoidance behavior. Given this phenotype, it was hypothesized that male B6.D2 Alcp1 mice would have lower levels of EW Ucn compared with B6.B6 mice, whereas female B6.B6 and B6.D2 Alcp1 mice would be equivalent. Figure 6 shows that, as anticipated, EW Ucn cell number and density were markedly decreased in male B6.D2 Alcp1 mice $\left(F_{(1,26)}=\right.$ 7.24, $p<0.05$, and $F_{(1,26)}=11.77, p<0.005$, respectively), whereas there were no differences in the EW Ucn cells and density in female control and congenic mice $\left(F_{(1,15)}<1\right.$, NS, and $F_{(1,21)}<$ $1, \mathrm{NS}$, respectively). LS processes were not analyzed because brain sections from the septal regions were not collected.

\section{Ucn profile in Edinger-Westphal-lateral septum of mice} selectively bred for high and low alcohol consumption On the basis of the data presented above, it appears that alterations in the Ucn system are related to the dichotomous alcohol drinking behaviors of B6 and D2 mice. However, it is important to provide confirmation of these findings in a population of mice not derived solely from the B6 and D2 strains. Additionally, B6 and D2 mice are behaviorally different in many ways (Crawley et al., 1997), and a stronger confirmation of the involvement of the EW-LS Ucn pathway in alcohol consumption could come from analyses performed in animals selectively bred for differences in alcohol drinking. Therefore, we analyzed the Ucn system in two replicate lines of alcohol-naive HAP and LAP mice that were selectively bred from a heterogeneous stock of mice (HS/Ibg) for differences in alcohol consumption in a continuous two-bottle choice paradigm (Grahame et al., 1999). Analysis of EW Ucn content in these mice revealed marked differences in Ucn cell 
Two-Bottle Choice
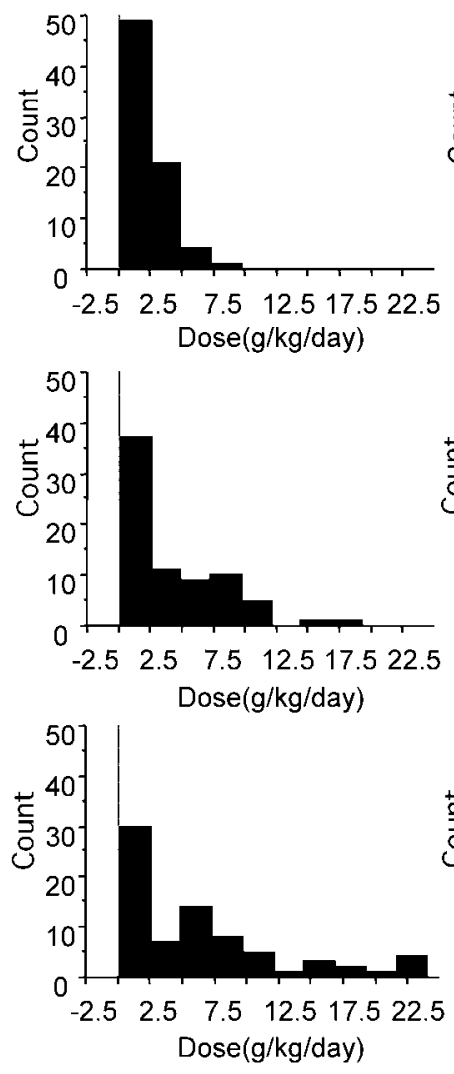
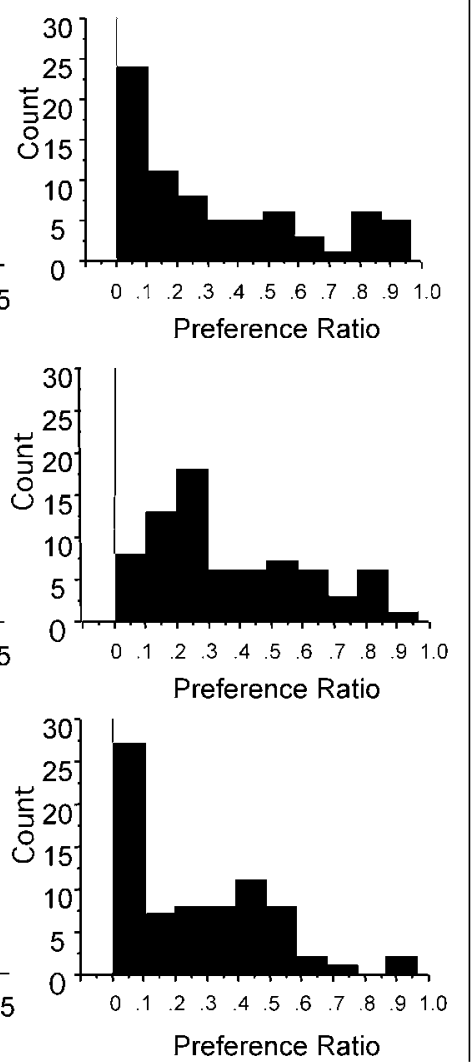

\section{Limited Access}
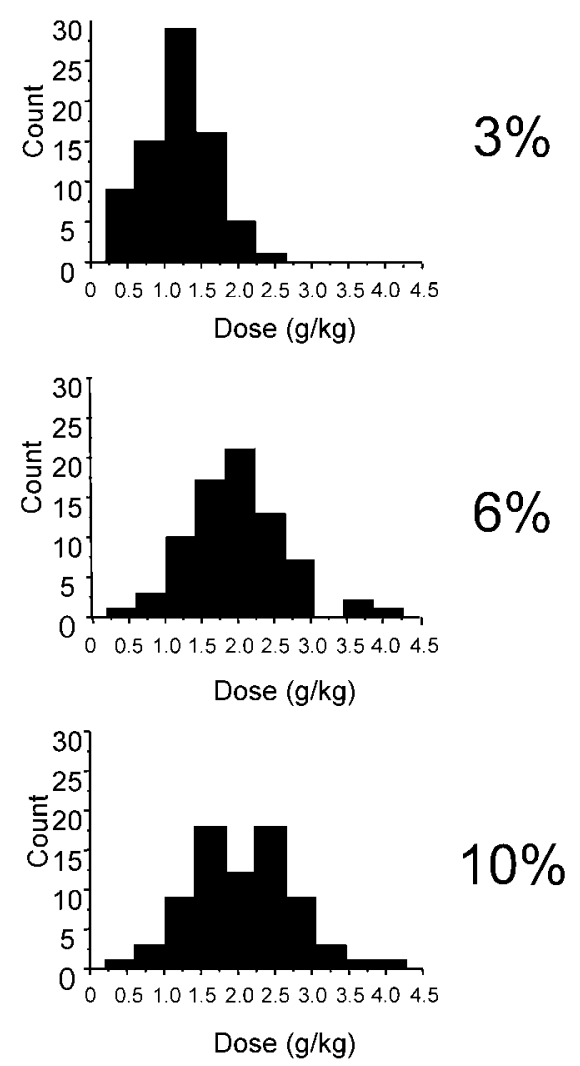

Figure 4. Frequency distributions of B6D2 F2 intercross mice during the continuous two-bottle choice procedure (two left pane/s) and the 30 min limited access ethanol/sucrose procedure (right panel). The left panel corresponds to total consumption of the ethanol solution at $3 \%$ (top), $6 \%$ (middle), and 10\% (bottom) concentrations. The middle panel corresponds to preference ratio (ethanol consumed/total fluid consumed) at the $3 \%$ (top), $6 \%$ (middle), and 10\% (bottom) concentrations. Note the skewed distributions in both consumption and preference in the $24 \mathrm{hr}$ two-bottle procedure. The tendencies to not drink in this procedure may have limited the ability to detect significant relationships with Ucn expression. The right panel corresponds to the consumption of a $3 \%$ ethanol/10\% sucrose (top), $6 \%$ ethanol $/ 10 \%$ sucrose (middle), and $10 \%$ ethanol $/ 10 \%$ sucrose (bottom).

Table 2. Correlation coefficients of B6D2 F2 consumption measures and EW-LS Ucn parameters

\begin{tabular}{lccc}
\hline Phenotypic measure & $\begin{array}{c}\text { Total EW } \\
\text { Ucn cells }\end{array}$ & EW Ucn density & LS Ucn processes \\
\hline Two-bottle choice paradigm & & & \\
3\% Et0H preference & 0.027 & 0.087 & -0.081 \\
6\% Et0H preference & 0.029 & 0.076 & -0.054 \\
10\% EtOH preference & 0.029 & 0.070 & 0.046 \\
3\% Et0H dose & 0.090 & 0.211 & -0.191 \\
6\% Et0H dose & 0.066 & 0.184 & -0.045 \\
$10 \%$ EtOH dose & -0.016 & 0.071 & -0.041 \\
Limited-access paradigm & & & \\
$10 \%$ sucrose consumption & 0.061 & 0.021 & -0.151 \\
10\% sucrose $/ 3 \%$ EtOH dose & 0.213 & 0.214 & $-0.267^{*}$ \\
$10 \%$ sucrose $/ 6 \%$ EtOH dose & 0.180 & 0.227 & $-0.315^{*}$ \\
$10 \%$ sucrose $/ 10 \%$ EtOH dose & $0.366^{* *}$ & $0.409^{* *}$ & $-0.246^{*}$ \\
\hline
\end{tabular}

*Statistical significance $(p<0.05)$; ${ }^{* *}$ statistical significance $(p<0.005)$.

EtOH, Ethanol.

number and Ucn expression levels (Fig. 7). In both replicate lines, HAP mice displayed higher Ucn cell numbers than LAP mice (replicate 1: $F_{(1,29)}=17.19, p<0.001$; replicate $2: F_{(1,28)}=20.71$; $p<0.001)$. Similar differences were detected with Ucn optical density measures in the EW (replicate 1: $F_{(1,29)}=22.77 ; p<$ 0.001 ; replicate $\left.2: F_{(1,29)}=32.16 ; p<0.001\right)$. Analysis of LS Ucn processes revealed differences between the HAP and LAP lines of only replicate 1 mice; HAP1 mice had more Ucn processes in the
LS compared with LAP1 mice $\left(F_{(1,24)}=9.92 ; p<0.005\right)$. There was no difference in the numbers of LS Ucn-positive processes of replicate $2 \mathrm{HAP} / \mathrm{LAP}$ mice $\left(F_{(1,25)}<1\right.$, NS).

\section{Discussion}

The results of this report identify and characterize the involvement of EW Ucn and the major forebrain target of EW, the LS, in the consumption of alcohol-containing solutions in several mouse models. Herein, this system was identified by the detection of c-Fos expression changes in EW and LS in B6 and D2 mice consuming an ethanol/sucrose solution. Changes observed between strains are likely related to the amount of ethanol consumed, which is consistent with previous findings showing dosedependent c-Fos expression after injections (Bachtell et al., 2002). Importantly, however, characterization of this system reveals that a genetic predisposition to high and low alcohol consumption involves differences of the EW-LS Ucn pathway. This notion is not novel to the $\mathrm{CRF} / \mathrm{Ucn}$ system. George and colleagues (1990) demonstrated that Wistar rats showing high alcohol preferences possess elevated CRF-like immunoreactivity in the hypothalamus. Comparisons in CRF levels and electroencephalographic activity between the alcohol preferring and nonpreferring selected lines of rats show that preferring rats have depressed CRF levels in the hypothalamus, amygdala, and cortex while also having enhanced electroencephalographic responses to exogenous CRF (Ehlers et al., 1992). It is therefore conceivable 

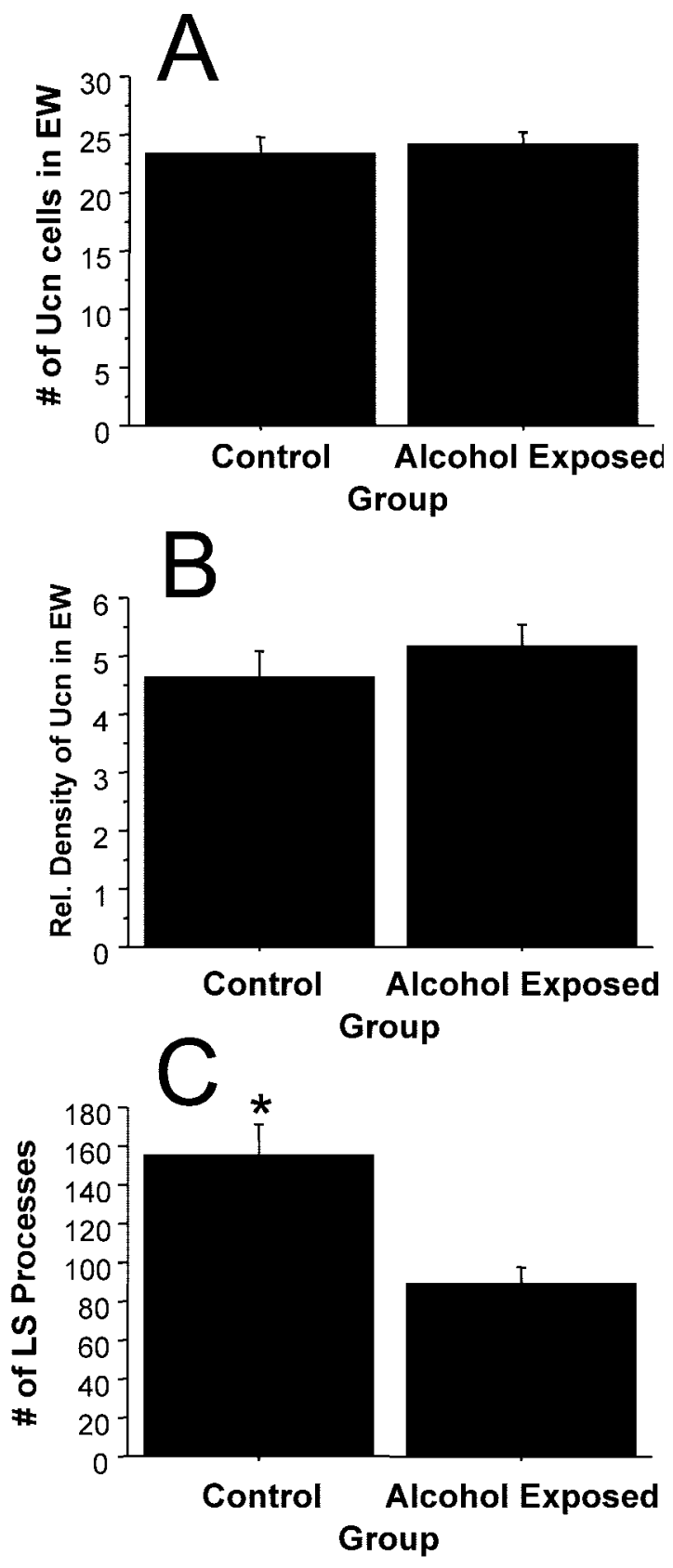

Figure 5. Consumption of ethanol in the B6D2 F2 mice appeared to have no effect on the number of Ucn-positive cells $(A)$ or expression of Ucn in EW $(B)$, but had significant suppressive effects on the number of Ucn-positive processes in the LS (C). ${ }^{*}$ Significant difference from corresponding group $(p<0.001)$.

that differences in other components of this system could exist in animals predisposed to high and low alcohol consumption.

Using c-Fos mapping, the EW has received considerable attention as a primary neural target after both voluntary and involuntary routes of administration (Chang et al., 1995; Ryabinin et al., 1997; Topple et al., 1998; Bachtell et al., 1999; Ryabinin et al., 2001; Weitemier et al., 2001). Until now, the role of the EW has been characterized primarily for oculomotor functions (Westphal, 1887; Warwick, 1954; Roste and Dietrichs, 1988; Burde and Williams, 1989; Trimarchi, 1992; Klooster et al., 1993). However, mounting evidence is forcing a change on this traditional view of EW function. Accordingly, the EW is suggested to be involved in thermoregulation, nociception, and anxiolysis (Innis

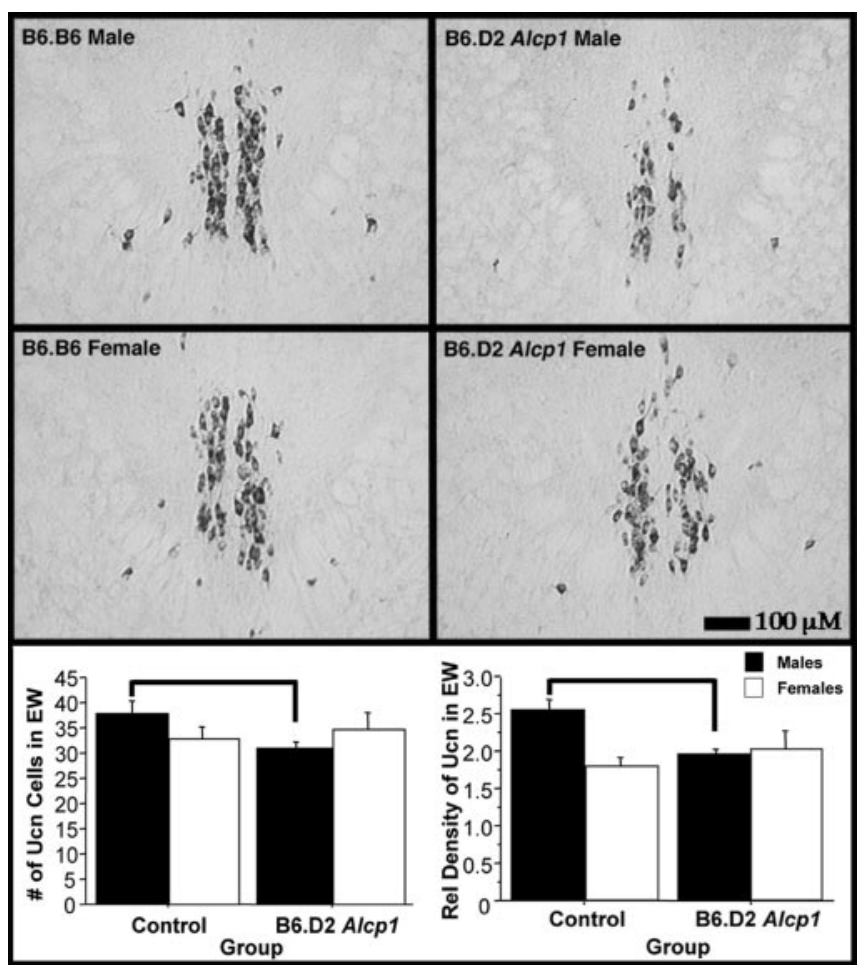

Figure 6. Analysis of the EW in the B6.D2 Alcp 1 line 2.2 congenic and B6.B6 mice revealed differing levels of Ucn expression (top pane/s). Quantification revealed that male B6.D2 Alcp1 line 2.2 mice possess significantly lower numbers of Ucn-positive cells than the control B6.B6 males ( $p<0.05$; indicated with bar), whereas females of the two strains did not differ (bottom left panel). Likewise, significantly lower expression levels were observed in the male B6.D2 Alcp 1 line 2.2 mice ( $p<0.005$; indicated with bar) but not in the female mice (bottom right panel). No comparisons were made between male and female mice because the sections from each sex were processed separately. Separately processed sections show variability in the intensity of signals and therefore may skew quantitative comparison.

and Aghajanian, 1986; Smith et al., 1998; Weninger et al., 1999; Bachtell et al., 2002).

This idea is supported by preferential Ucn expression in the EW (Vaughan et al., 1995; Yamamoto et al., 1998; Bittencourt et al., 1999; Morin et al., 1999; Weninger et al., 2000). Ucn is structurally and functionally similar to CRF and the recently discovered peptides Ucn II and Ucn III/Stresscopin (Hsu and Hsueh, 2001; Lewis et al., 2001; Reyes et al., 2001). Actions of Ucn are mediated by activity at CRHR1 or CRHR2 G-protein-coupled receptors (Chang et al., 1993; Chen et al., 1993; Perrin et al., 1993; Vita et al., 1993; Kishimoto et al., 1995; Lovenberg et al., 1995; Perrin et al., 1995). It has been shown that Ucn binds to both of these receptors with an affinity equal to or greater than that of CRF (Eckart et al., 1999).

The results presented here build on the notion that the EW is more functionally diverse than originally portrayed and support its role in alcohol-related phenotypes. This agrees with recently characterized differences in the structure of the EW between the B6 and D2 strains of mice, including marked differences in the Ucn system (Bachtell et al., 2002). This report demonstrated that higher Ucn expression in the EW is positively correlated with increased sensitivity to the hypothermic response to alcohol. This finding was confirmed in HOT1 and COLD1 selected lines of mice, which were selected based on their susceptibility (COLD) or resistance (HOT) to heat loss after a high $(3.0 \mathrm{gm} / \mathrm{kg})$ dose of alcohol. 

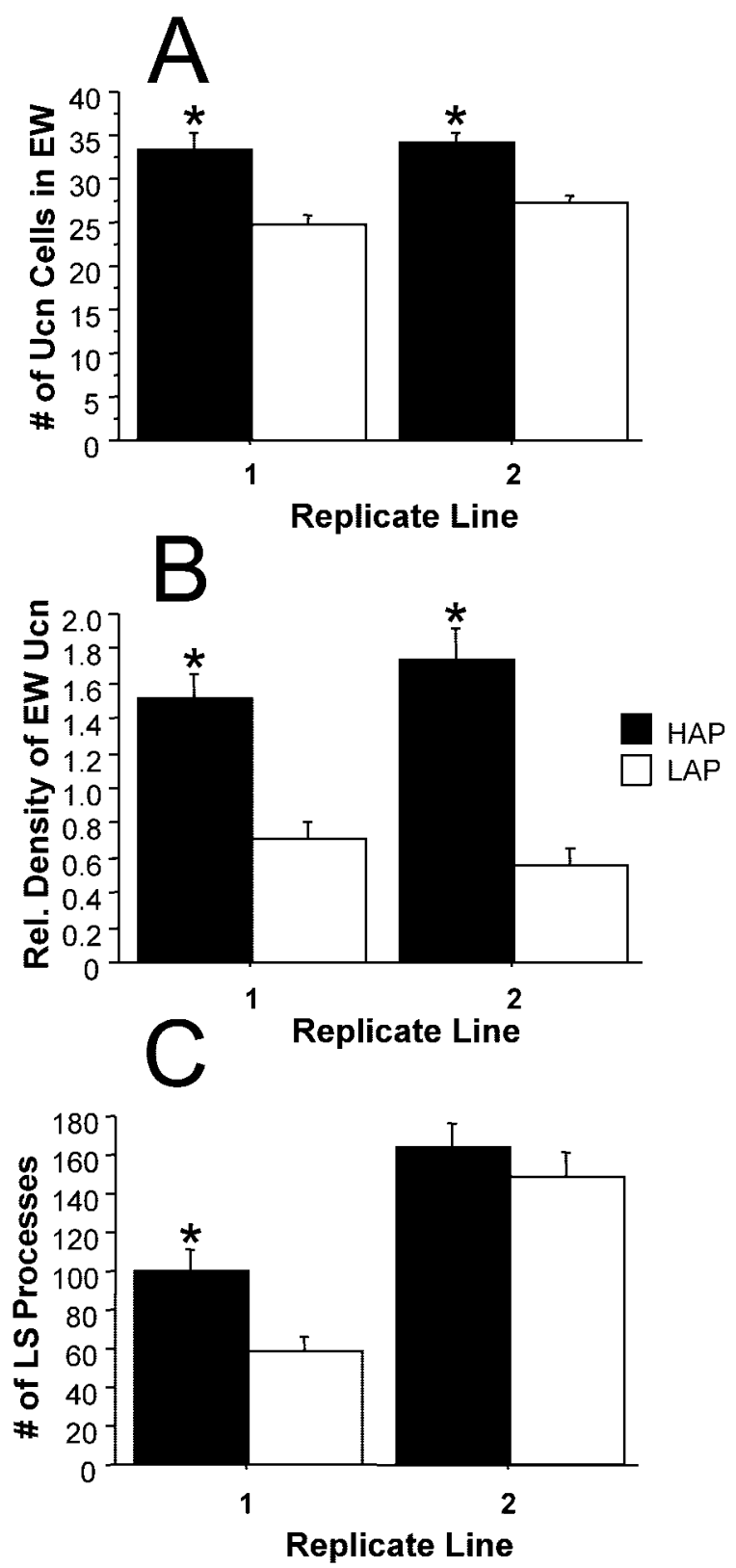

Figure 7. Quantification of Ucn levels in the EW and LS of HAP and LAP mice revealed significant differences between these lines of mice selectively bred for differences in alcohol preference measures. $A$, Both replicate lines of HAP mice possess more Ucn-positive cells in the EW. $B$, Similarly, both replicate lines of the HAP mice have higher Ucn expression levels than corresponding LAP mice. C, Analysis of Ucn-positive LS processes revealed significantly larger numbers in the HAP mice of replicate 1 but not of replicate 2 . *Significantly different from corresponding line $(p<0.01)$.

Alcohol-induced hypothermia has been shown to genetically correlate with some of the hedonic properties of alcohol (Crabbe et al., 1996; Risinger and Cunningham, 1998). Cunningham and colleagues (1991) showed that the HOT/COLD selected lines of mice differ on several measures of the hedonic effects of alcohol, including conditioned place preference, alcohol drinking, and conditioned taste aversion. Specifically, COLD1 mice willingly ingested alcohol solutions at high concentrations. As would be expected on the basis of the results presented in this report, COLD1 mice have high levels of EW Ucn expression, whereas HOT1 mice possess low levels of Ucn expression (Bachtell et al.,
2002). Thus, a relationship also appears to exist in these mice in which high levels of Ucn in the EW predict high alcohol consumption. The present study finds a positive correlation between alcohol consumption and measures of Ucn in the EW in B6D2 F2 offspring and B6.D2 Alcp1 2.2 congenic mice. In addition, the presence of higher Ucn levels in both replicate 1 and 2 of HAP versus LAP selected mice argues against the idea of genetic drift as a cause for the correlation between $U c n$ levels and alcohol intake and strongly implicates the involvement of Ucn in ethanol drinking.

Interestingly, these genetic models are not the only evidence that the Ucn system is involved in alcohol consumption. Further support stems from characterization of alcohol-drinking behaviors in mice with a targeted deletion of the CRF prohormone (Muglia et al., 1995). Although possessing no CRF, compensatory enhancement of Ucn expression exists in the EW of these mice (Weninger et al., 2000). Importantly, homozygous CRF knockout mice show enhanced alcohol drinking in the two-bottle choice test, whereas there are no apparent differences in total fluid consumption, taste preferences, or alcohol clearance (Olive et al., 2002). Taken together, data from several genetic models provide sound evidence to support a relationship between high Ucn expression in the EW and high alcohol consumption.

In the present study, the LS was also suggested to be involved in alcohol consumption as revealed through the c-Fos mapping performed in B6 and D2 mice in which alcohol/sucrose drinking tended to suppress sucrose-induced c-Fos expression in the intermediate and dorsal regions of the LS. This agrees with our recent finding that c-Fos expression is suppressed in the LS of B6 mice voluntarily consuming excessively high amounts of alcohol (2.9 gm/kg in $30 \mathrm{~min}$ ) (Ryabinin et al., 2003). Importantly, c-Fos suppression in the LS could be specific for voluntarily consumed alcohol because it was not observed in studies that passively administered alcohol (Ryabinin et al., 1997). This is supported by 2-deoxyglucose brain mapping procedures in which oral selfadministration produced ethanol-specific changes in the LS, whereas passive administration did not (Williams-Hemby and Porrino, 1994; Porrino et al., 1998).

Importantly, the LS is the primary Ucn projection region in the forebrain (Bittencourt et al., 1999). High levels of CRHR2 receptors exist in the septum, and it is thought that $U \mathrm{cn}$ terminals in the intermediate LS target these receptors because of the sixfold greater affinity of Unc for CRHR2 over CRF (Vaughan et al., 1995; Van Pett et al., 2000). CRF receptors in the septum have been shown to inhibit extracellular recording potentials after intracerebroventricular administration of CRF (Siggins et al., 1985). This concurs with the suppression of c-Fos after alcohol consumption. On the other hand, although we hypothesize that regulation of the LS occurs through projections from the EW, it is alternatively possible that suppressive effects of alcohol in the hippocampus seen here in D2 mice, and in earlier studies in rodents, also suppress LS activity (Risold and Swanson, 1997; Ryabinin et al., 1997).

Characterization of the LS between the alcohol-preferring, B6, and alcohol-avoiding, D2, strains revealed that D2 mice possess higher numbers of Ucn processes compared with B6 mice. This finding was strengthened in the analysis of the B6D2 F2 intercross, in which a negative correlation between alcohol consumption and LS Ucn processes exists. It can be hypothesized that enhanced numbers of Ucn projections in the LS provide overcompensation for decreased Ucn levels in the EW. This is not compatible with the results from the HAP/LAP selected lines of mice, in which large Ucn differences were detected in the EW, but 
no differences were observed in the LS of replicate 2 and large increases were seen in the alcohol-preferring HAP1 mice. This argues against overcompensation in the LS of the $\mathrm{B} 6 / \mathrm{D} 2$ mice versus HAP/LAP mice, whose genetic origins are different. Although not analyzed here, other biochemical phenotypes (e.g., CRHR2 expression and/or affinity) in the septum of HAP/LAP mice may provide compensation, rendering functional effects of increased Ucn processes similar to that observed in D2 mice and low alcohol consumers in the B6D2 F2 intercross. Moreover, the analysis of the B6D2 intercross results, but not the HAP/LAP results, is complicated by the potential ability of alcohol drinking to regulate the number of Ucn-positive processes in LS identified here.

In conclusion, the results of the c-Fos expression study and Ucn analysis in several inbred strains and selectively bred mouse lines provide strong evidence to support a role of Ucn-positive cells in the EW for regulating alcohol consumption. Additionally, these data provide suggestive evidence that EW Ucn cells can influence alcohol consumption via their projections to the LS, a brain region capable of regulating fluid consumption and brain reward mechanisms (Miller and Mogenson, 1971; Taghzouti et al., 1985; Cazala et al., 1988). However, the complexity of the relationship between Ucn projections to the LS and alcohol drinking found in our study indicate that further efforts are needed to elucidate the role of Ucn and CRH receptors in the LS for alcohol consumption.

\section{References}

Bachtell RK, Wang YM, Freeman P, Risinger FO, Ryabinin AE (1999) Alcohol drinking produces brain region-selective changes in expression of inducible transcription factors. Brain Res 847:157-165.

Bachtell RK, Tsivkovskaia NO, Ryabinin AE (2002) Strain differences in urocortin expression in the Edinger-Westphal nucleus and its relation to alcohol-induced hypothermia. Neuroscience 113:421-434.

Belknap JK, Crabbe JC, Young ER (1993) Voluntary consumption of ethanol in 15 inbred mouse strains. Psychopharmacology 112:503-510.

Bittencourt JC, Vaughan J, Arias C, Rissman RA, Vale WW, Sawchenko PE (1999) Urocortin expression in rat brain: evidence against a pervasive relationship of urocortin-containing projections with targets bearing type 2 CRF receptors. J Comp Neurol 415:285-312.

Burde RM, Williams F (1989) Parasympathetic nuclei. Brain Res 498: 371-375.

Cazala P, Galey D, Durkin T (1988) Electrical self-stimulation in the medial and lateral septum as compared to the lateral hypothalamus: differential intervention of reward and learning processes? Physiol Behav 44:53-59.

Chang C-P, Pearse II RV, O'Connell S, Rosenfeld MG (1993) Identification of a seven transmembrane helix receptor for corticotropin-releasing factor and sauvagine in mammalian brain. Neuron 11:1187-1195.

Chang SL, Patel NA, Romero AA (1995) Activation and desensitization of Fos immunoreactivity in the rat brain following ethanol administration. Brain Res 679:89-98.

Chen R, Lewis KA, Perin MH, Vale WW (1993) Expression cloning of a human corticotropin-releasing-factor receptor. Proc Natl Acad Sci USA 90:8967-8971.

Crabbe JC, Phillips TJ, Gallaher EJ, Crawshaw LI, Mitchell SR (1996) Common genetic determinants of the ataxic and hypothermic effects of ethanol in BXD/Ty recombinant inbred mice: genetic correlations and quantitative trait loci. J Pharmacol Exp Ther 277:624-632.

Crawley JN, Belknap JK, Collins A, Crabbe JC, Frankel W, Henderson N, Hitzemann RJ, Maxson SC, Miner LL, Silva AJ, Wehner JM, WynshawBoris A, Paylor R (1997) Behavioral phenotypes of inbred mouse strains: implications and recommendations for molecular studies. Psychopharmacology 132:107-124.

Cunningham CL, Hallett CL, Niehus DR, Hunter JS, Nouth L, Risinger FO (1991) Assessment of ethanol's hedonic effects in mice selectively bred for sensitivity to ethanol-induced hypothermia. Psychopharmacology 105:84-92.

Eckart K, Radulovic J, Radulovic M, Jahn O, Blank T, Stiedl O, Spiess J (1999) Actions of CRF and its analogs. Curr Med Chem 6:1035-1053.

Ehlers CL, Chaplin RI, Wall TL, Lumeng L, Li TK, Owens MJ, Nemeroff CB
(1992) Corticotropin releasing factor (CRF): studies in alcohol preferring and non-preferring rats. Psychopharmacology 106:359-364.

Erichsen JT, May PJ (2002) The pupillary and ciliary components of the cat Edinger-Westphal nucleus: a transsynaptic transport investigation. Vis Neurosci 19:15-29.

Franklin KBJ, Paxinos G (1997) The mouse brain in stereotaxic coordinates. San Diego: Academic.

George SR, Fan T, Roldan L, Naranjo CA (1990) Corticotropin-releasing factor is altered in brains of animals with high preference for ethanol. Alcohol Clin Exp Res 14:425-429.

Grahame NJ, Li TK, Lumeng L (1999) Selective breeding for high and low alcohol preference in mice. Behav Genet 29:47-57.

Grant KA, Samson HH (1985) Induction and maintenance of ethanol selfadministration without food-deprivation in the rat. Psychopharmacology 86:475-479.

Hsu SY, Hsueh AJ (2001) Human stresscopin and stresscopin-related peptide are selective ligands for the type 2 corticotropin-releasing hormone receptor. Nat Med 7:605-611.

Innis RB, Aghajanian GK (1986) Cholecystokinin-containing and nociceptive neurons in rat Edinger-Westphal nucleus. Brain Res 363:230-238.

Kishimoto T, Pearse II RV, Lin CR, Rosenfeld MG (1995) A sauvagin/ corticotropin-releasing factor receptor expressed in heart and skeletal muscle. Proc Natl Acad Sci USA 92:1108-1112.

Klooster J, Beckers HJM, Vrensen GFJM, VanderWant JJL (1993) The peripheral and central projections of the Edinger-Westphal nucleus in the rat. A light and electron microscopic tracing study. Brain Res 632:260-273.

Kozicz T, Arimura A, Maderdrut JL, Lazar G (2002) Distribution of urocortin-like immunoreactivity in the central nervous system of the frog Rana esculenta. J Comp Neurol 453:185-198.

Lewis K, Li C, Perrin MH, Blount A, Kunitake K, Donaldson C, Vaughan J, Reyes TM, Gulyas J, Fischer W, Bilezikjian L, Rivier J, Sawchenko PE, Vale WW (2001) Identification of urocortin III, an additional member of the corticotropin-releasing factor (CRF) family with high affinity for the CRF2 receptor. Proc Natl Acad Sci USA 98:7570-7575.

Lovenberg TW, Liaw CW, Grogoriadis DE, Clevenger W, Chalmers DT, Desouza EB, Oltersdorf T (1995) Cloning and characterization of a functionally distinct corticotropin-releasing factor receptor subtype from rat brain. Proc Natl Acad Sci USA 92:836-840.

McClearn GE, Rodgers DA (1959) Differences in alcohol preference among inbred strains of mice. Q J Stud Alcohol 20:691-695.

Miller JJ, Mogenson GJ (1971) Modulatory influences of the septum on lateral hypothalamic self stimulation. Exp Neurol 33:671-683.

Morgan JI, Curran T (1991) Stimulus-transcription coupling in the nervous system: involvement of the inducible proto-oncogenes fos and jun. Annu Rev Neurosci 14:421-451.

Morgan JI, Cohen DR, Hempstead JL, Curran T (1987) Mapping patterns of c-fos expression in the central nervous system after seizure. Science 236:192-197.

Morin SM, Ling N, Liu X-J, Kahl SD, Gehlert DR (1999) Differential distribution of urocortin- and corticotropin-releasing factor-like immunoreactivities in the rat brain. Neuroscience 92:281-291.

Muglia L, Jacobson L, Dikkes P, Majzoub JA (1995) Corticotropin-releasing hormone deficiency reveals major fetal but not adult glucocorticoid need. Nature 373:427-432.

Olive MF, Mehmert KK, Koenig HN, Camarini R, Kim JA, Nannini MA, Ou CJ, Hodge CW (2002) A role for corticotropin releasing factor (CRF) in ethanol consumption, sensitivity, and reward as revealed by CRFdeficient mice. Psychopharmacology 165:181-187.

Perrin MH, Donaldson CJ, Chen R, Blount A, Beggren T, Bilezikjian L, Sawchenko P, Vale W (1993) Cloning and functional expression of a rat brain corticotropin releasing factor (CRF) receptor. Endocrinology 133:3058-3061.

Perrin M, Donaldson C, Chen R, Blount A, Berggren T, Bilezikjian L, Sawchenko P, Vale W (1995) Identification of a second corticotropinreleasing factor receptor gene and characterization of a cDNA expressed in heart. Proc Natl Acad Sci USA 92:2969-2973.

Porrino LJ, Williams-Hemby L, Whitlow C, Bowen C, Samson HH (1998) Metabolic mapping of the effects of oral alcohol self-administration in rats. Alcohol Clin Exp Res 22:176-182.

Reyes TM, Lewis K, Perrin MH, Kunitake KS, Vaughan J, Arias CA, Hogenesch JB, Gulyas J, Rivier J, Vale WW, Sawchenko PE (2001) Urocortin II: 
a member of the corticotropin-releasing factor (CRF) neuropeptide family that is selectively bound by type 2 CRF receptors. Proc Natl Acad Sci USA 98:2843-2848.

Risinger FO, Cunningham CL (1998) Ethanol-induced conditioned taste aversion in BXD recombinant inbred mice. Alcohol Clin Exp Res 22:1234-1244.

Risold PY, Swanson LW (1997) Connections of the rat lateral septal complex. Brain Res Brain Res Rev 24:115-195.

Roste GK, Dietrichs E (1988) Cerebellar cortical and nuclear afferents from the Edinger-Westphal nucleus in the cat. Anat Embryol 178:59-65.

Ryabinin AE, Criado JR, Henriksen SJ, Bloom FE, Wilson MC (1997) Differential sensitivity of c-Fos expression in hippocampus and other brain regions to moderate and low doses of alcohol. Mol Psychiatry 2:32-43.

Ryabinin AE, Wang Y-M, Freeman P, Risinger FO (1999) Selective effects of alcohol drinking on restraint-induced expression of immediate early genes in mouse brain. Alcohol Clin and Exp Res 23:1272-1280.

Ryabinin AE, Bachtell RK, Freeman P, Risinger FO (2001) ITF expression in mouse brain during acquisition of alcohol self-administration. Brain Res 890:192-195.

Ryabinin AE, Galvan-Rosas A, Bachtell RK, Risinger FO (2003) High alcohol/sucrose consumption during dark circadian phase in C57BL/6J mice: involvement of hippocampus, lateral septum and urocortin-positive cells of the Edinger-Westphal nucleus. Psychopharmacology 165:296-305.

Saper CB (1996) Any way you cut it: a new journal policy for the use of unbiased counting methods. J Comp Neurol 364:5.

Sagar SM, Sharp FR, Curran T (1988) Expression of c-fos protein in brain: metabolic mapping at a cellular level. Science 240:1328-1331.

Siggins GR, Gruol D, Aldenhoff J, Pittman Q (1985) Electrophysiological actions of corticotropin-releasing factor in the central nervous system. Fed Proc 44:237-242.

Skelton KH, Owens MJ, Nemeroff CB (2000) The neurobiology of urocortin. Regul Pept 93:85-92.

Smith JE, Jansen AS, Gilbey MP, Loewy AD (1998) CNS cell groups projecting to sympathetic outflow of tail artery: neural circuits involved in heat loss in the rat. Brain Res 786:153-164.

Taghzouti K, Simon H, Tazi A, Dantzer R, Le Moal M (1985) The effect of 6-OHDA lesions of the lateral septum on schedule-induced polydipsia. Behav Brain Res 15:1-8.

Topple AN, Hunt GE, McGregor IS (1998) Possible neural substrates of beer-craving in rats. Neurosci Lett 252:99-102.
Trimarchi F (1992) Neuro-ophtalmology. Curr Opin Neurol Neurosurg 5:740-743.

Van Pett K, Viau V, Bittencourt JC, Chan RK, Li HY, Azias C, Prins GS, Perrin M, Vale W, Sawchenko PE (2000) Distributions of mRNAs encoding CRF receptors in brain and pituitary of rat and mouse. J Comp Neurol 428:191-212.

Vaughan J, Donaldson C, Bittencourt J, Perrin MH, Lewis K, Sutton S, Chan R, Turnbull AV, Lovejoy D, Rivier C, Rivier J, Sawchenko PE, Vale W (1995) Urocortin, a mammalian neuropeptide related to fish urotensin I and to corticotropin-releasing factor. Nature 378:287-292.

Vita N, Laurent P, Lefort S, Chalon P, Lelias JM, Kaghad M, LeFur G, Caput D, Ferrara P (1993) Primary structure and functional expression of mouse pituitary and human brain corticotropin releasing receptors. FEBS Lett 335:1-5.

Warwick RB (1954) The ocular parasympathetic nerve supply and its mesencephalic sources. J Anat (Lond) 88:71-93.

Weitemier AZ, Woerner A, Backstrom P, Hyytia, Ryabinin AE (2001) Expression of c-Fos in Alko alcohol rats responding for ethanol in an operant paradigm. Alcohol Clin Exp Res 25:704-710.

Weninger SC, Dunn AJ, Muglia LJ, Dikkes P, Miczek KA, Swiergiel AH, Berridge CW, Majzoub JA (1999) Stress-induced behaviors require the corticotropin-releasing hormone $(\mathrm{CRH})$ receptor, but not $\mathrm{CRH}$. Proc Natl Acad Sci USA 96:8283-8288.

Weninger SC, Peters LL, Majzoub JA (2000) Urocortin expression in the Edinger-Westphal nucleus is up-regulated by stress and corticotropinreleasing hormone deficiency. Endocrinology 141:256-263.

Westphal C (1887) Über einen Fall von chronischer progressive Lähming des Augenmuskeln (Ophthalmoplegia externa) nebst Beschreibung von Ganglienzellengruppen in Bereiche des Oculomotoriuskerns. Arch Psychiat Nervenheilk 98:846-871.

Whatley VJ, Johnson TE, Erwin VG (1999) Identification and confirmation of quantitative trait loci regulating alcohol consumption in congenic strains of mice. Alcohol Clin Exp Res 23:1262-1271.

Williams-Hemby L, Porrino LJ (1994) Low and moderate doses of ethanol produce distinct patterns of cerebral metabolic changes in rats. Alcohol Clin Exp Res 18:982-988.

Yamamoto H, Maeda T, Fujimura M, Fujimiya M (1998) Urocortin-like immunoreactivity in the substantia nigra, ventral tegmental area and Edinger-Westphal nucleus of rat. Neurosci Lett 243:21-24. 